\title{
An experimental and constitutive investigation on the chemo-mechanical behaviour of a clay
}

\author{
P. WITTEVEEN*, A. FERRARI* and L. LALOUI*
}

\begin{abstract}
Engineering issues for which the understanding of the chemo-mechanical behaviour of soils is relevant include wellbore stability problems, the salinification of groundwater, and nuclear waste storage. However, despite the vast number of situations in which couplings between chemistry and mechanics occur, the available constitutive models rely on limited experimental evidence. This paper presents the results of an experimental programme on the chemo-mechanical behaviour of a non-swelling illite. The osmotic suction is controlled through the ion concentration of sodium chloride in the pore water. Stress paths include mechanical loading at a constant osmotic suction, and an increasing osmotic suction at a constant mechanical stress. The experimental results point out a correlation between the osmotic suction and initial oedometric modulus, as well as between the osmotic suction and yield stress. A constitutive framework for soils is extended to take the observed chemo-mechanical couplings into account. The numerical model has been calibrated for the illite using the parameters obtained through the tests under mechanical loading at a constant concentration, and validated using more elaborate stress paths. The presented experimental and constitutive investigation builds a basis for the assessment of engineering issues in which pore liquid chemistry plays a major role.
\end{abstract}

KEYWORDS: chemical properties; clays; constitutive relations; laboratory tests; suction

\section{INTRODUCTION}

Understanding couplings between the chemical composition of the pore liquid and the mechanical behaviour in clayey soils is becoming essential in the practice of civil, energy and environmental engineering. While the applications were previously limited to groundwater pollution problems (e.g. for drinking water, or with respect to plant growth), the relevance of knowledge on the behaviour of clay soils subject to influences of a chemical type is now significant in many fields, including the storage of nuclear waste (degradation of concrete liners), oil and gas wellbore stability (entrance of drill fluid in soil), and/or soil stabilisation.

The effects of electrolytes in contact with the clay soil's pore liquid have been researched since the 1950s. Early contributions, such as Bolt (1956) and Bolt \& Miller (1955), focused mainly on soil compressibility. In the 1970s and 1980s, chemically induced consolidation, permeability and shear strength variations, and osmosis and osmotic effects were extensively studied (e.g. Mesri \& Olson, 1970, 1971; Mitchell et al., 1973; Sridharan \& Venkatappa Rao, 1973, 1979; Marine \& Fritz, 1981; Fritz, 1986; Barbour \& Fredlund, 1989). The late 1990s and 2000s brought forth coupled chemo-mechanical models, in which the concentration or mass fraction of certain species in the pore liquid played a major role (e.g. Loret et al., 2002; Gajo \& Loret, 2003; Gens, 2010; Guimarães et al., 2007).

This study aimed to extend the experimental database on the subject of one-dimensional consolidation induced by a change in the chemical composition of the pore liquid, with a focus on electrolytes. A laboratory programme was carried out, under which the experimental results were modelled within a new constitutive framework.

Manuscript received 5 March 2012; revised manuscript accepted 17 October 2012.

Discussion on this paper closes on 1 August 2013, for further details see p. ii.

* Laboratory for Soil Mechanics, Swiss Federal Institute of Technology Lausanne, Switzerland.

\section{THEORIES AND EVIDENCE}

It is widely acknowledged that clays exhibit a negative electrical charge at their platy particle surface (e.g. Mitchell \& Soga, 2005). Thus their aggregates, the groups of parallelarranged platelets, exhibit this negative electrical charge all along their outer boundaries, leading clays to attract positively charged ions from the pore liquid, and the diffuse double layer to be constructed (Gouy, 1910; Chapman, 1913; Verwey \& Overbeek, 1948). The high concentration of cations and the low concentration of anions at the clay boundary result in a high electrical potential, which decreases as the distance from the aggregate increases. This potential causes the clay to act as a non-ideal, semi-permeable membrane, reducing the migration of electrically charged ions but allowing electrically neutral water molecules to move freely. The so-called 'osmotic processes' resulting from these properties have been widely described in the literature (e.g. Marine \& Fritz, 1981; Fritz, 1986; Barbour \& Fredlund, 1989; Loret et al., 2002).

The migration of ions or water may alter the pore liquid composition in two distinct ways. First, a chemical concentration gradient can lead to the entry of ions into the pores, where the negatively charged clay aggregate boundaries will attract the positively charged cations. Thus the interaggregate repulsive forces decrease, leading the modal pore diameter and therefore the overall volume to decrease. This phenomenon is referred to as chemical consolidation. Second, if there is a chemical concentration gradient and the higher concentration is on the outside of the considered soil mass, water flows out of the soil owing to the osmotic effects occurring in clays with thick, diffuse double layers (or high electrical potential along their particle surfaces) with respect to the pore diameter. This outflow increases the negative pore liquid pressure and thus the effective stress (total stress minus pore water pressure), leading to an overall volume reduction. This phenomenon is referred to as osmotic consolidation.

These two main phenomena may occur in parallel, because the semi-permeable properties of the clay are not 
ideal. Various authors use different terminology for these phenomena: Barbour \& Fredlund (1989) mention osmotic consolidation and osmotically induced consolidation, whereas Kaczmarek \& Hueckel (1998) discuss chemical consolidation and chemico-osmotic consolidation.

Barbour \& Fredlund (1989) interpreted the results of a series of four experiments conducted by Mesri \& Olson (1971), and presented additional experimental results on two different types of soil to quantify 'osmotic compressibility and permeability'. The main conclusion of their work was that the dominant mechanism of volume change was osmotic consolidation, referred to as chemical consolidation here.

Consolidation due to a difference in chemical composition of the pore water was investigated by Fernandez \& Quigley $(1985,1991)$ and later by Hueckel (1997) and Boukpeti et al. (2004). They studied the influence of a single organic contaminant on the compressibility properties of Sarnia clay, which is an Na-montmorillonite with traces of Ca-smectite. Hueckel (1997) and Boukpeti et al. (2004) modelled mainly the evolution of the yield limit stress. They proposed a logarithmic evolution law, under which the yield stress decreases as the contaminant concentration increases, defined as the 'chemical softening function'.

Di Maio (1996), Di Maio \& Fenelli (1997) and Di Maio \& Onorati (1999) described a series of experiments with the aim of evidencing and quantifying the aforementioned consolidation phenomena without naming them. The main part of their research was focused on a bentonite, yielding large deformations (up to $15 \%$ due to a change in pore liquid only). Constitutive models based on these results were proposed by Loret et al. (2002), Gajo \& Loret (2003), and Gajo et al. (2002) under one framework, and by Gens (2010) and Guimarães et al. (2007) under a different framework.

The former framework (Loret et al., 2002; Gajo \& Loret, 2003) consists of an elasto-plastic model in which the chemical part is governed by the mass fractions and mass balance of all of the species in the soil sample. In contrast, the latter framework (Gens, 2010; Guimarães et al., 2007) consists of a double-structured model in which the chemical part is represented by osmotic suction. This osmotic suction works at the microscopic level, and all of the strains it produces are considered completely reversible.

A chemo-poro-elasticity model for shales was presented by Bunger (2010) and Sarout \& Detournay (2011). The model is an extension of classic Biot poro-elasticity (Biot, 1941, 1956a, 1956b, 1973), including the evolution of pore pressures through a sample due to the presence and transport of ions in the pore liquid. Based on the work of Sherwood (1993, 1994), Heidug \& Wong (1996) and Coussy (2004), the joint papers described the effects of mechanical perturbations (due to a pore liquid pressure gradient) and chemical perturbations (due to a pore liquid concentration gradient) in a pore pressure transmission experiment. Sarout \& Detournay (2011) presented a fully described elastic model. These models for shales are defined in terms of the chemical composition of the pore liquid, taking the quantities of different species or components in the pore water into account.

With increasing interest in geomechanical applications in which the chemistry of the pore liquid plays a major role, advanced chemo-mechanical frameworks are increasingly important. This paper proposes a coupled elasto-plastic, chemo-mechanical model. In contrast to previous studies, where the (ion) concentration was considered as the governing variable, the present model is defined for changes in osmotic suction, which allows the results to be presented and discussed independently of the pore liquid components.

\section{EXPERIMENTAL PROGRAMME}

A comprehensive laboratory programme was conducted with the aim of providing additional experimental evidence on: (a) a 'chemical softening function', an evolution law for the yield limit stress with respect to the pore liquid chemistry; and (b) deformation due to chemical loading. The programme involved a series of chemo-mechanical experiments in which the osmotic suction was controlled through the sodium chloride concentration in the pore water.

\section{Materials}

Solutions of sodium chloride $(\mathrm{NaCl})$ in distilled water at different ion concentrations, ranging from $0.0 \mathrm{M}$ (distilled water) to $6.0 \mathrm{M}$ (practically saturated sodium chloride solution), were mixed with a non-swelling illite powder. The mineralogy, Atterberg limits and initial conditions of the illite powder and its grain size distribution are presented in Table 1. Because of the fairly low activity of the illite, the chemo-mechanical behaviour is quite different from that in other studies reported in the literature.

During preparation, a mass of illite powder was mixed with the appropriate amount of solution. The mixture was cured in a sealed plastic chamber for a minimum of $24 \mathrm{~h}$ to guarantee the internal redistribution of the pore liquid.

\section{Suction measurements}

Osmotic suction is a function of the ion concentration, and for dilute solutions (ion concentrations up to approx. 2.0 M), it can be approximated by the Van't Hoff equation as

$$
\pi=v R T c
$$

where $\pi$ is the osmotic suction $(\mathrm{kPa}), v$ is the number of constituent ions, $R$ is the universal gas constant $(\mathrm{J} /(\mathrm{mol} \mathrm{K}))$, $T$ is the absolute temperature $(\mathrm{K})$, and $c$ is the ion concentration of the electrolyte. A first series of experiments was performed to obtain a correlation between the osmotic suction and ion concentration that was valid for the entire range of applied sodium chloride concentrations. The matric and total suction of the clay powder-pore liquid mixtures were

Table 1. Mineralogy, Atterberg limits, grain size distribution and physical data of soil used in experiments

Mineralogy

\begin{tabular}{l|c}
\hline Illite: \% & 77 \\
Kaolinite: \% & 10 \\
Calcite: \% & 12 \\
Quartz: & Traces \\
Feldspar & Traces \\
\hline
\end{tabular}

Atterberg limits

\begin{tabular}{l|l}
\hline Liquid limit: \% & 54 \\
Plastic limit: \% & 30 \\
Plasticity index: \% & 24 \\
\hline
\end{tabular}

Grain-size distribution

Sand fraction: \%

Silt fraction: \% 12

Clay fraction: \%

Physical data

Hygroscopic water content: \% (at 40\% RH)

Grain density: $\mathrm{g} / \mathrm{cm}^{3}$

Specific surface: $\mathrm{m}^{2} / \mathrm{g}$ 
first determined by the filter paper method, using Schleicher and Schuell no. $589 / 2 \quad 40.5 \mathrm{~mm}$ dia. filter papers. The suction values of the filter paper were calibrated with respect to the water content for the matric suction (difference between pore air and pore water pressures) and the total suction (matric suction plus osmotic suction) separately. The calibration involved use of the axis-translation technique to control the matric suction, and the vapour equilibrium technique to control the total suction of the filter paper.

Five of the mixtures were prepared with distilled water at different water contents; four additional mixtures were prepared with a $4.0 \mathrm{M}$ solution at different water contents. Additionally, the total suction of clay powder-pore liquid mixtures prepared at different sodium chloride target concentrations (distilled water, $0.5,1 \cdot 0,2 \cdot 0,4 \cdot 0$ and $6 \cdot 0 \mathrm{M}$ ) and at different water contents was determined using a chilledmirror dew-point psychrometer (Leong et al., 2003; Cardoso et al., 2007). The water content of all mixtures was determined after the tests by oven-drying at $105^{\circ} \mathrm{C}$ until no mass change occurred in the last $24 \mathrm{~h}$.

\section{Chemo-mechanical oedometric tests}

Chemo-mechanical oedometric tests were conducted involving changes in the vertically applied mechanical stress and osmotic suction. The goal of this research programme was to highlight changes in the yield stress and elasto-plastic parameters of the clay material.

The specimens were prepared by compacting a clay powder-pore liquid mixture directly in the oedometer rings (60 $\mathrm{mm}$ in diameter and $10 \mathrm{~mm}$ high), targeting an initial void ratio of $e_{0}=0.95 \pm 0.02$. The compaction energy was kept constant for all samples. With the density of the solutions in the range $\rho_{\text {solution }}=1 \cdot 10 \pm 0 \cdot 10 \mathrm{Mg} / \mathrm{m}^{3}$, this resulted in an initial water content of $w_{0}=0 \cdot 39 \pm 0 \cdot 05$, corresponding to fully saturated conditions. The typical loading time for mechanical increments was $24 \mathrm{~h}$.

The osmotic suction and vertically applied mechanical stress (corresponding to the vertical effective stress) were the independent driving variables. Therefore there were two types of stress increment, mechanical and chemical, which allowed the elaborate stress paths to be defined.

The experimental programme was designed such that the influence of osmotic suction on the mechanical behaviour could be researched first. To this end, a series of seven oedometer tests were conducted at different but constant values of osmotic suction of the pore liquid. Two of the samples were prepared with distilled water; the five others were prepared with one of the aforementioned solutions.

The influence of changes in osmotic suction was then investigated through two experiments in which there was an incremental concentration change at different but constant mechanical stress levels. Two oedometric samples were prepared with distilled water and loaded mechanically up to different vertical stress levels $\left(\sigma_{\mathrm{v}}=30 \mathrm{kPa}\right.$ and $\left.\sigma_{\mathrm{v}}=77 \mathrm{kPa}\right)$. The chemical loading was achieved by replacing the oedometer cell fluid with an electrolyte of higher osmotic suction and monitoring the deformation of the sample until it stabilised after 2-4 days. The surrounding solution was frequently renewed to ensure the ion concentration in the sample. The incremental approach meant that this procedure was repeated for different osmotic suctions, until a saturated sodium chloride solution was applied in the last step. Afterwards, these chemically loaded samples were subjected to the remaining loading increments of the conventional mechanical oedometric test.

The previously described stress paths are quantitatively represented in Figs 1 and 2. In both the mechanical and the

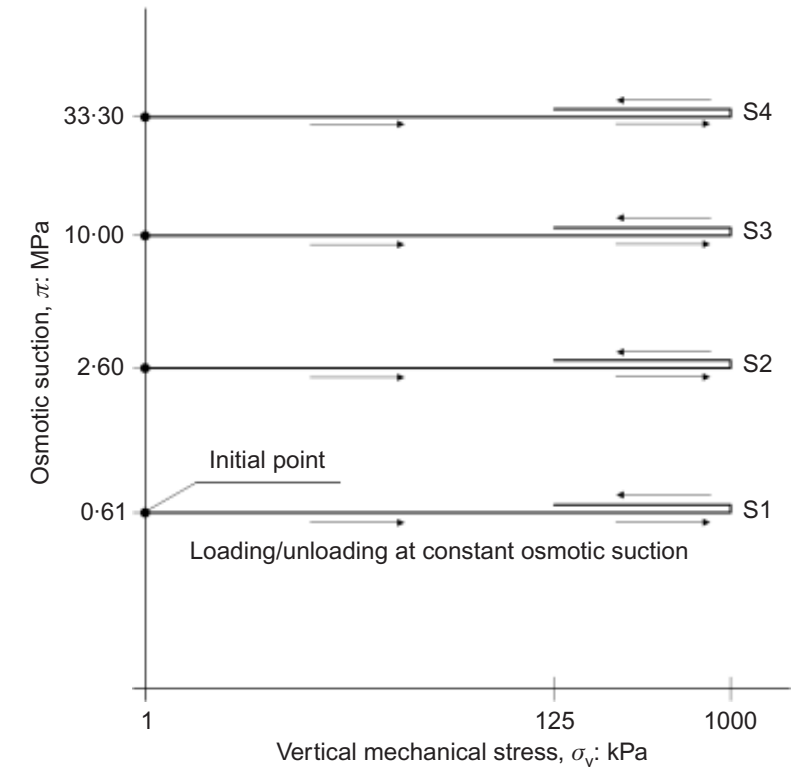

Fig. 1. Applied stress paths for oedometer samples under mechanical loading only

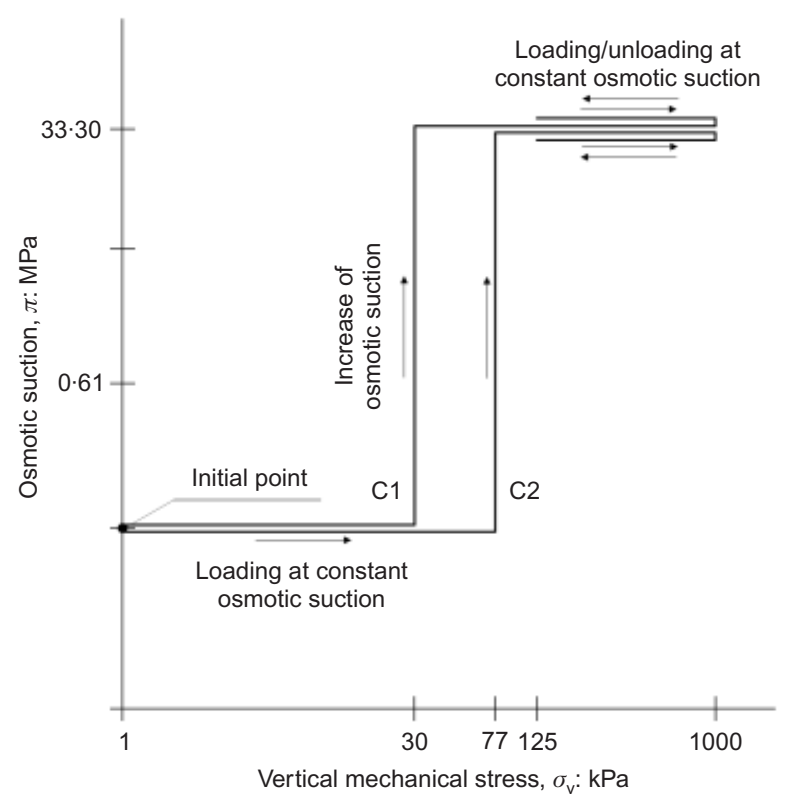

Fig. 2. Applied stress paths for oedometer samples under mechanical and chemical loading

chemical loading increments, secondary compression is not taken into account.

Table 2 provides an overview of all the tests performed.

\section{EXPERIMENTAL RESULTS}

\section{Suction measurements}

Figure 3 depicts the results of the filter paper method and the psychrometric readings for the mixtures prepared with distilled water and with the $4.0 \mathrm{M}$ solution. The total suction $\psi(\mathrm{MPa})$ and matric suction $s_{\mathrm{m}}(\mathrm{MPa})$ are plotted against the water content of the mixtures of illite powder with either distilled water or a $4.0 \mathrm{M}$ sodium chloride solution. In the distilled water mixtures, the matric suction is two orders of magnitude smaller than the total suction. This effect is even larger (three to four orders of magnitude) for the mixtures prepared with the salt solution, because the presence of salt increases the osmotic component of the suction, while the 
Table 2. Overview of all tests performed

\begin{tabular}{|c|c|c|c|}
\hline & \multicolumn{3}{|c|}{ Tested material } \\
\hline & Solutions of sodium chloride in distilled water & $\begin{array}{l}\text { Mixtures of clay powder } \\
\text { with distilled water }\end{array}$ & $\begin{array}{l}\text { Mixtures of clay powder with solutions of } \\
\text { sodium chloride }\end{array}$ \\
\hline Suction measurement & $\begin{array}{l}\text { Total suction determination by psychrometric } \\
\text { readings for different concentrations of }\end{array}$ & \multicolumn{2}{|c|}{$\begin{array}{l}\text { Matric and total suction determination by filter paper method and } \\
\text { psychrometric readings for different water content values }\end{array}$} \\
\hline $\begin{array}{l}\text { Mechanical oedometer } \\
\text { tests }\end{array}$ & & $\begin{array}{l}\text { Two loading-unloading } \\
\text { tests }\end{array}$ & $\begin{array}{l}\text { Five loading-unloading tests at } \\
\text { concentrations of } 0 \cdot 5,1 \cdot 0,2 \cdot 0,4 \cdot 0 \text { and } \\
6.0 \mathrm{M}\end{array}$ \\
\hline $\begin{array}{l}\text { Chemo-mechanical } \\
\text { oedometer tests }\end{array}$ & & \multicolumn{2}{|c|}{$\begin{array}{l}\text { Two loading-unloading tests with chemical loading at constant } \\
\text { vertical stress }\end{array}$} \\
\hline
\end{tabular}

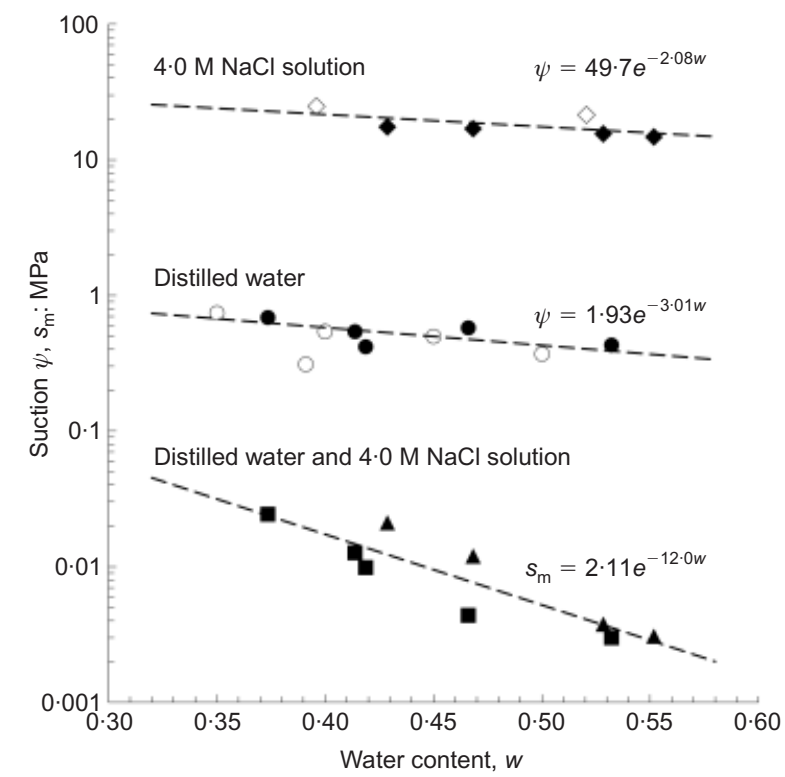

Dist. water; total suction (psychrometer)

- Dist. water; total suction (filter paper)

- Dist. water; matric suction (filter paper)

$\checkmark 4.0 \mathrm{M}$; total suction (psychrometer)

- $4.0 \mathrm{M}$; total suction (filter paper)

- $4.0 \mathrm{M}$; matric suction (filter paper)

Fig. 3. Total and matric suction measurements on mixtures of illite powder and either distilled water or $4 \cdot 0 \mathrm{M}$ sodium chloride (NaCl) solution

matric suction remains fairly constant. These results indicate that the presence of salt in the pore water does not significantly influence the matric suction. Thus the measurements in terms of total suction are subsequently assumed to be representative of the osmotic component, and in the following the matric suction will be neglected. However, this assumption might be different for other types of clay and salt, because the interaction between clay and salt might be of a different nature.

Figure 3 also shows the marginal influence of the water content on the osmotic suction for the considered range. Within the range of initial water contents for the oedometric specimens, the osmotic suctions are of the same order of magnitude. Therefore the influence of the water content in this range can be neglected.

The test results show that the osmotic suction measured for the specimens prepared with distilled water is greater than zero. This measurement can be explained by the dissolution of ions from the clay powder, as the illite can exchange cations. This finding allowed an average initial osmotic suction $\pi_{0}=0.61 \mathrm{MPa}$ for the average initial water content $w_{0}=0.39$ to be determined. This value will be the intercept in the correlation between the ion concentration and osmotic suction.

Finally, the results of the total suction measurements with both the filter paper method and dew-point psychrometer are plotted in Fig. 4 as a function of the sodium chloride concentration. Psychrometer readings for sodium chloride solutions prepared at different concentrations are also reported.

The graph shows a monotonic dependence of increasing suction with increasing ion concentration that can be appropriately described with a polynomial of the second order. The fact that the suction values for both the solutions and mixtures lie on the same line confirms that the influence of the matrix on the osmotic suction, as well as the influence of the presence of salt on the matric suction, is negligible.

The regression line in Fig. 4 provides an empirical relationship for the osmotic suction (in $\mathrm{MPa}$ ) in a mixture of illite and a sodium chloride solution as a function of the ion

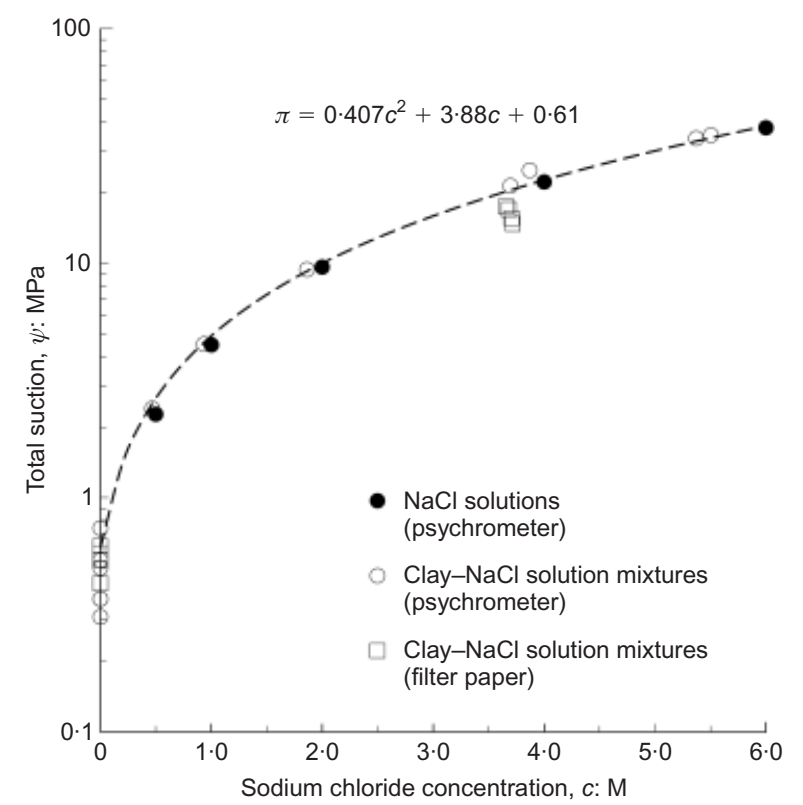

Fig. 4. Empirical relationship between osmotic suction of clay samples and sodium chloride $(\mathrm{NaCl})$ concentration of pore water 
concentration of that solution for the applied range of ion concentrations. The relationship is described with the function

$$
\pi=f(c)=0 \cdot 407 c^{2}+3 \cdot 888 c+0 \cdot 61
$$

\section{Chemo-mechanical oedometric tests}

For clarity, the results of only four of the tests under mechanical loading are plotted in Fig. 5. Three major observations follow from these oedometric curves.

(a) The initial stiffness of the material decreases as the osmotic suction increases.

(b) The yield stress (the stress at the transition point from the elastic into the elasto-plastic behaviour) decreases as the osmotic suction increases.

(c) The slopes of the normal consolidation line (NCL) and unloading-reloading line (URL) do not change significantly with respect to the osmotic suction.

Observation (a) is confirmed when plotting the initial oedometric modulus (the applied stress increment from 1 to $15 \mathrm{kPa}$, divided by the occurring strain difference) against the osmotic suction, as shown in Fig. 6. There is a power trend, where the oedometric modulus decreases as the osmotic suction increases.

Observation (b) is confirmed by plotting the yield stress against the osmotic suction, as shown in Fig. 7. There is a logarithmic correlation, whereby the mechanical yield stress decreases as the osmotic suction increases. This conclusion corresponds to the proposed correlation between the preconsolidation pressure and concentration of one (organic) contaminant by Hueckel (1997) and Boukpeti et al. (2004). A new mathematical form is proposed in the present study for the evolution of the yield limit stress with respect to the osmotic suction of the pore water, as

$$
\sigma_{\mathrm{c}}=\left(1-\gamma_{\pi} \log \frac{\pi}{\pi_{0}}\right) \sigma_{\mathrm{c} 0}
$$

where $\sigma_{\mathrm{c}}$ is the vertical yield stress $(\mathrm{kPa}), \gamma_{\pi}$ is the chemical evolution factor, $\pi$ is the current osmotic suction (MPa), $\pi_{0}=0.61 \mathrm{MPa}$ is the osmotic suction for the samples prepared with distilled water, and $\sigma_{\mathrm{c} 0}$ is the vertical yield stress at $\pi_{0}$.

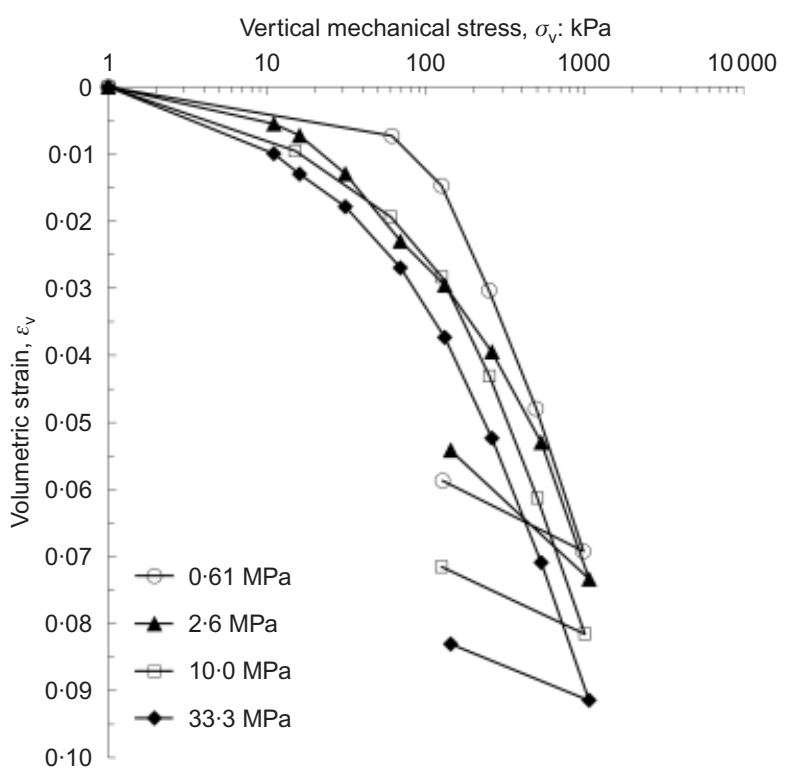

Fig. 5. Oedometric curves of four of the oedometric tests under mechanical loading only with different osmotic suctions

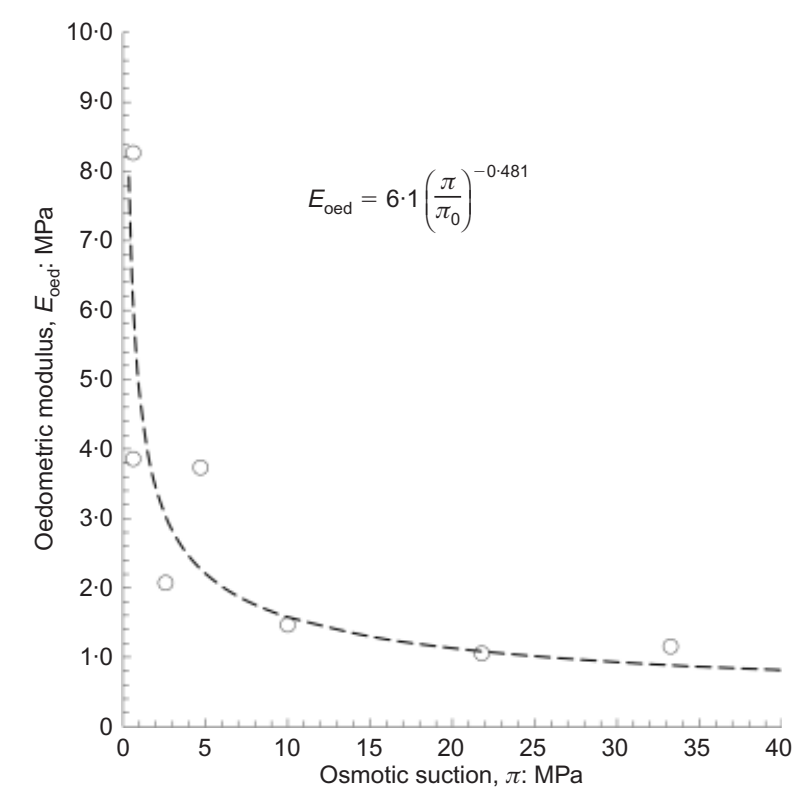

Fig. 6. Empirical correlation between initial oedometric modulus upon first loading (vertical stress $1-15 \mathrm{kPa}$ ) and osmotic suction of mixtures of illite powder and sodium chloride solutions at different osmotic suctions

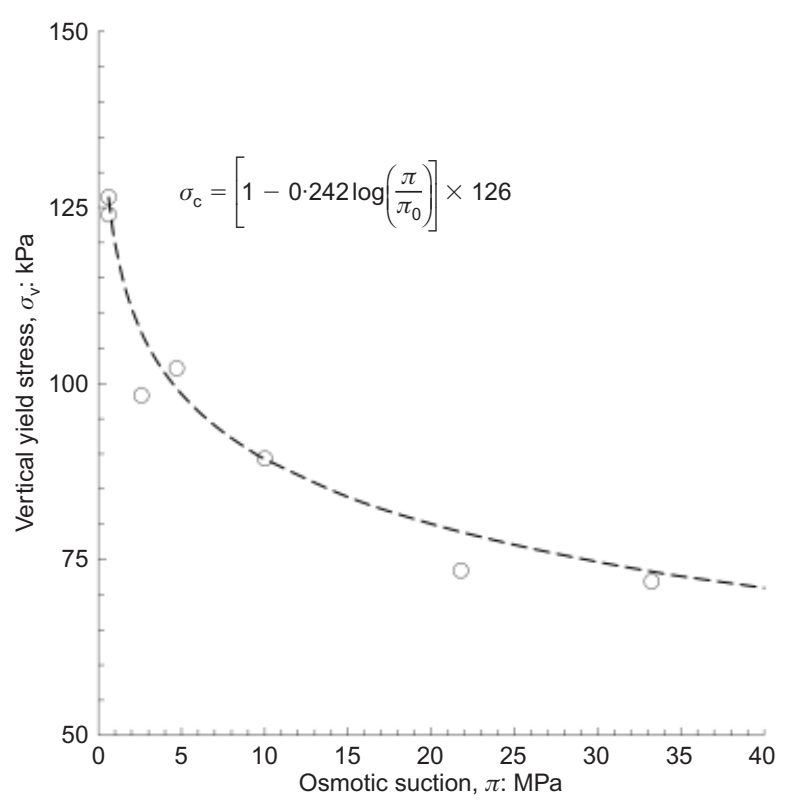

Fig. 7. Correlation between vertical mechanical yield stress and osmotic suction of mixtures of illite powder and sodium chloride solutions at different osmotic suctions

Observation (c) is confirmed when the compression and swelling indices are plotted against the osmotic suction, as shown in Fig. 8. The diagram shows that the slopes of the NCL and URL remain almost constant. However, the high swelling index for the sample at $\pi=2.6 \mathrm{MPa}$ is clearly distinguished.

The results of the two tests including chemical loading increments (stress paths $\mathrm{C} 1$ and $\mathrm{C} 2$ in Fig. 2) are presented in Fig. 9. In both cases, the clay underwent consolidation due to a change in the osmotic suction. From the incremental approach, it shows that this volumetric strain $\varepsilon_{\mathrm{V}}$ follows a straight line in the $\varepsilon_{\mathrm{V}}-\log \pi$ diagram (Fig. 10). This rate of consolidation due to chemical loading does not change significantly within the applied void ratio and vertical mechanical stress ranges. 


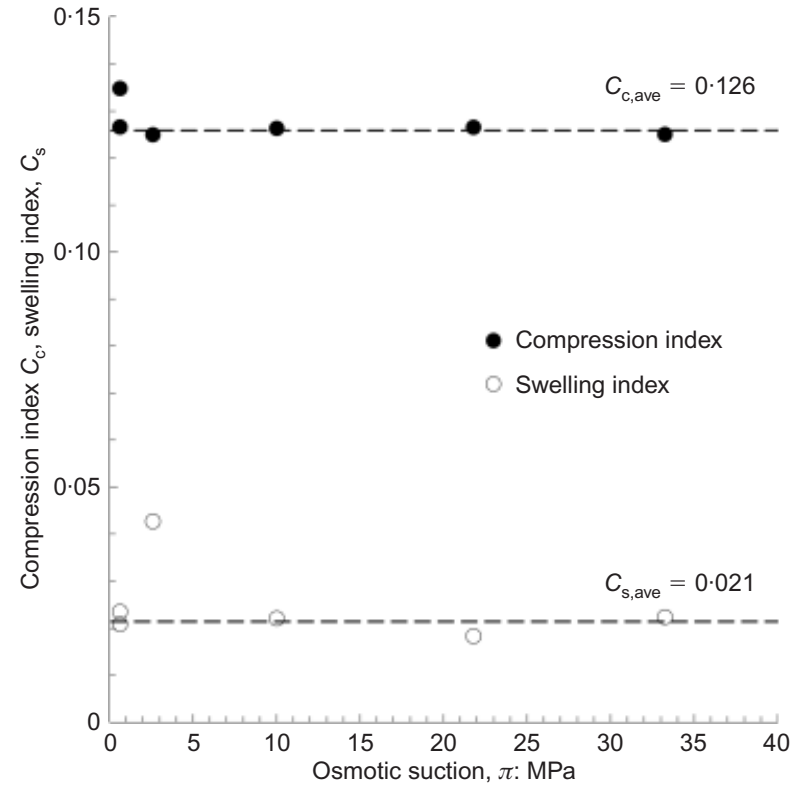

Fig. 8. Compression and swelling indices against osmotic suction of mixtures of illite powder and sodium chloride solutions at different osmotic suctions

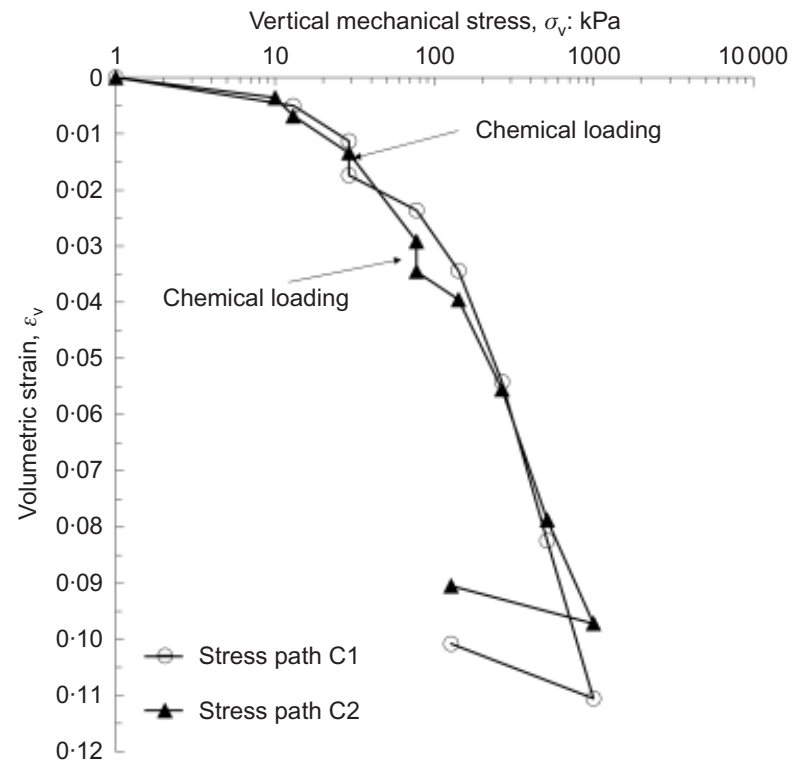

Fig. 9. Oedometric curves of the two tests under mechanical and chemical loading

\section{CONSTITUTIVE FRAMEWORK}

The results of the oedometric tests under mechanical loading allowed an innovative extension of a constitutive framework to be developed, with the aim of reproducing and quantitatively predicting the observed chemo-mechanical behaviour. This framework is based on the Hujeux model (Hujeux, 1979). Existing extensions of it are known under the name ACMEG (advanced constitutive model for environmental geomechanics; Laloui et al., 2010). They can cope with partial saturation (Laloui \& Nuth, 2009), thermoplasticity for saturated soil (Laloui \& François, 2009) and unsaturated soils (François \& Laloui, 2008), and double-structured geomaterials (Koliji et al., 2010), among other variables.

The current extension, ACMEG-C (chemical effect), is able to account for changes in osmotic suction as well as the evolution of the elastic and plastic material parameters and the plastic deformation induced by these changes.

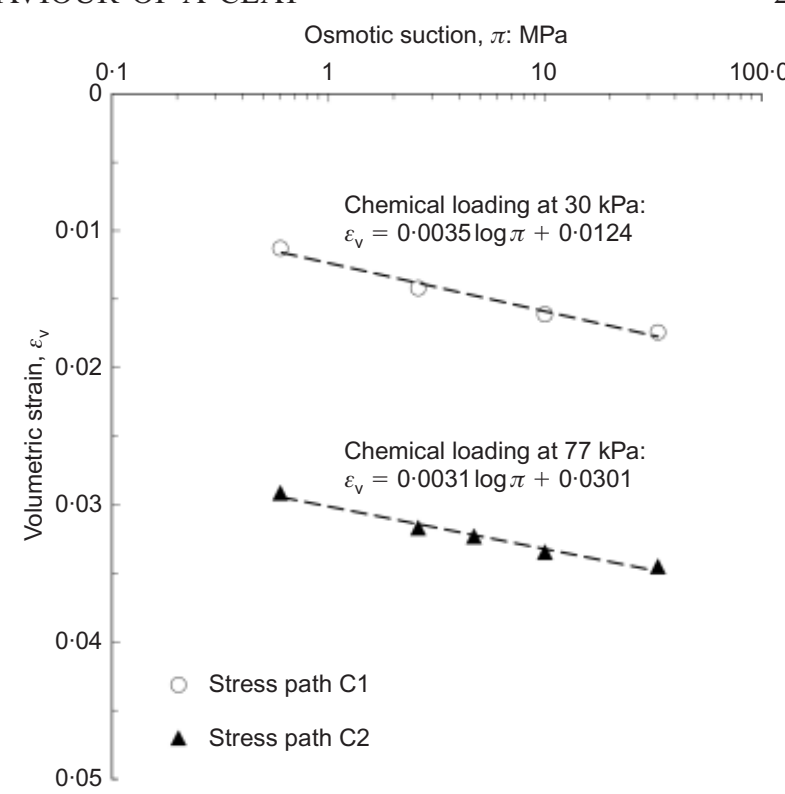

Fig. 10. Consolidation due to an incremental increase in osmotic suction with respect to osmotic suction

ACMEG-C is a soil-plasticity-based model for chemomechanical formulations. To take the loading history of the soil into account, ACMEG-C is defined in terms of infinitesimal increments. Elasto-plasticity implies the existence of a loading surface in both mechanical stress and osmotic suction that defines an elastic region in which only reversible deformations occur. The concept of elasto-plasticity allows the total strain increment, $\mathrm{d} \varepsilon_{i j}$, to be divided into chemo-elastic, $\mathrm{d} \varepsilon_{i j}^{\mathrm{e}}$, and chemo-plastic components, $\mathrm{d} \varepsilon_{i j}^{\mathrm{p}}$,

$$
\mathrm{d} \varepsilon_{i j}=\mathrm{d} \varepsilon_{i j}^{\mathrm{e}}+\mathrm{d} \varepsilon_{i j}^{\mathrm{p}}
$$

The constitutive model is conceived in terms of the following conjugate stress-strain variables

$$
\begin{aligned}
& p^{\prime}=\frac{1}{3} \operatorname{tr}\left(\boldsymbol{\sigma}^{\prime}\right) \text { and } \varepsilon_{\mathrm{v}}=\operatorname{tr}(\boldsymbol{\varepsilon}) \\
& q=\sqrt{3 J_{2 \mathrm{D}}} \text { and } \varepsilon_{\mathrm{d}}=\frac{2}{\sqrt{3}} \sqrt{I_{2 \mathrm{D}}}
\end{aligned}
$$

where $p^{\prime}$ is the mean effective stress, $q$ is the deviatoric stress, $\varepsilon_{\mathrm{v}}$ is the volumetric strain, $\varepsilon_{\mathrm{d}}$ is the deviatoric strain, and $J_{2 \mathrm{D}}$ and $I_{2 \mathrm{D}}$ are the second invariants of the strain and stress tensor respectively.

\section{Chemo-hypo-elasticity}

The elastic strains $\mathrm{d} \varepsilon_{i j}^{\mathrm{e}}$ are reversible, and do not affect the hardening state of the material. The elastic strain can be decomposed into chemo-elastic volumetric $\left(\mathrm{d} \varepsilon_{\mathrm{v}}^{\mathrm{e}}\right)$ and deviatoric $\left(\mathrm{d} \varepsilon_{\mathrm{d}}^{\mathrm{e}}\right)$ strains. They are computed as

$$
\begin{aligned}
\mathrm{d} \varepsilon_{\mathrm{v}}^{\mathrm{e}} & =\frac{\mathrm{d} p^{\prime}}{K} \\
\mathrm{~d} \varepsilon_{\mathrm{d}}^{\mathrm{e}} & =\frac{\mathrm{d} q}{3 G}
\end{aligned}
$$

The hypo-elastic moduli $K$ and $G$ are given by

$$
\begin{aligned}
& K=K_{\text {ref }}\left(\frac{p^{\prime}}{p_{\text {ref }}^{\prime}}\right)^{n^{\mathrm{e}}} \\
& G=G_{\text {ref }}\left(\frac{p^{\prime}}{p_{\text {ref }}^{\prime}}\right)^{n^{\mathrm{e}}}
\end{aligned}
$$


where $K_{\text {ref }}$ and $G_{\text {ref }}$ are the reference bulk and shear moduli of the material respectively, determined at a reference mean effective stress $p_{\text {ref }}^{\prime}$, and $n^{\mathrm{e}}$ is a material parameter.

According to the experimental findings on the evolution of the initial stiffness with respect to the osmotic suction (Fig. 6), the reference bulk modulus $K_{\text {ref }}$ is assumed to evolve with the osmotic suction following the power function

$$
K_{\text {ref }}=K_{\text {ref }, 0}\left(\frac{\pi}{\pi_{0}}\right)^{-\delta}
$$

where $K_{\text {ref, } 0}$ is the reference bulk modulus for a test at a reference osmotic suction.

\section{Chemo-plasticity}

The plastic strain increment can be expressed as the unrecoverable part of the total strain increment.

The particularity of the Hujeux model's plasticity framework is the fact that this total plastic strain increment is a linear combination of two irreversible processes: isotropic and deviatoric mechanisms. Each mechanism has its own yield function, $f_{\text {iso }}$ and $f_{\text {dev }}$ respectively. Therefore the total plastic strain increment is the sum of the 'partial' plastic strain increments, $\mathrm{d} \varepsilon_{i j}^{\mathrm{p}, k}$, for each mechanism's $k$

$$
\mathrm{d} \varepsilon_{i j}^{\mathrm{p}}=\sum_{k=1}^{2} \mathrm{~d} \varepsilon_{i j}^{\mathrm{p}, k}
$$

These considerations arise from the theory of multi-mechanism plasticity (Koiter, 1960; Mandel, 1965; Hujeux, 1979). Once the stress state reaches one of the yield functions, the corresponding evolution law is activated. Both irreversible processes depend on their respective dissipative potentials and plastic multipliers (Rizzi et al., 1996). This relationship can be expressed as

$$
\mathrm{d} \varepsilon_{i j}^{\mathrm{p}}=\sum_{k=1}^{2} \lambda_{k}^{\mathrm{p}} \frac{\partial g_{k}}{\partial \sigma_{i j}^{\prime}}
$$

where $g_{k}$ is the plastic potential and $\lambda_{k}^{\mathrm{p}}$ is the increment of the plastic multiplier of mechanism $k$. The latter is positive when the corresponding process is activated, and null otherwise. According to the multi-mechanism approach, these two yield functions form a closed domain in the effective stress and chemistry space, inside which the strains are reversible.

Isotropic chemo-plastic mechanism. The isotropic chemoplastic mechanism is defined in the $\pi-p^{\prime}$-plane, where $\pi$ is the osmotic suction of the material, and is expressed by

$$
f_{\text {iso }}=p^{\prime}-p_{\mathrm{c}}^{\prime} r_{\text {iso }}
$$

where $p^{\prime}$ is the current effective stress, $p_{\mathrm{c}}^{\prime}$ is the mean yield stress, and $r_{\text {iso }}$ is the degree of plastification (mobilised hardening) of the isotropic yield limit. Using this expression, the conceptual bilinearity of the elasto-plastic behaviour has been evened out, so that a smooth transition curvature can be represented. This implies a progressive evolution of the activated plastic strain according to the bonding surface theory, as presented by Dafalias \& Herrmann (1980) and François \& Laloui (2008).

During loading, $r_{\text {iso }}$ is a hyperbolic function of the volumetric plastic strain induced by the isotropic mechanism $\varepsilon_{\mathrm{v}}^{\mathrm{p} \text {,iso }}$ (Hujeux, 1979), and is expressed as

$$
r_{\text {iso }}=r_{\text {iso }}^{\mathrm{e}}+\frac{\varepsilon_{\mathrm{v}}^{\mathrm{p} \text {,iso }}}{c_{r}+\varepsilon_{\mathrm{v}}^{\mathrm{p}, \text { iso }}}
$$

$$
\mathrm{d} r_{\text {iso }}=\frac{\left(1-r_{\text {iso }}\right)^{2}}{c_{r}} \mathrm{~d} \varepsilon_{\mathrm{v}}^{\text {,iso }}
$$

where $c_{r}$ is a material parameter.

The yield limit stress is a function of the activated volumetric plastic strain and osmotic suction. Inserting the empirical relationship (equation (3)), and assuming that the functions for the vertical effective yield stress and the mean effective yield stress are of the same form, the yield limit is defined by the apparent preconsolidation stress as

$$
p_{\mathrm{c}}^{\prime}=p_{\mathrm{c} 0}^{\prime} \exp \left(\beta \varepsilon_{\mathrm{v}}^{\mathrm{p}}\right)\left(1-\gamma_{\pi} \log \frac{\pi}{\pi_{0}}\right)
$$

where $p_{\mathrm{c} 0}^{\prime}$ is the preconsolidation stress at a reference osmotic suction $\pi_{0}, \beta$ is the plastic stiffness modulus, $\varepsilon_{\mathrm{v}}^{\mathrm{p}}$ is the total plastic volumetric strain (produced by the two mechanisms), $\gamma_{\pi}$ is the material parameter defining the shape of the isotropic yield limit with respect to the osmotic suction, and $\pi$ is the current osmotic suction.

As the elastic stiffness is dependent on osmotic suction, and the normal compression line was observed experimentally to be constant, the plastic stiffness modulus $\beta$ (the inverse of the slope of the linear function $\varepsilon_{\mathrm{v}}^{\mathrm{p}}-\log p_{\mathrm{c}}^{\prime}$ ) was assumed dependent on the osmotic suction. A logarithmic correlation is proposed of the form

$$
\beta=\left(1+\gamma_{\beta} \log \frac{\pi}{\pi_{0}}\right) \beta_{0}
$$

where $\gamma_{\beta}$ is the chemical evolution factor, $\pi$ is the current osmotic suction $(\mathrm{MPa}), \pi_{0}$ is a reference osmotic suction, and $\beta_{0}$ is the plastic modulus at $\pi_{0}$.

Therefore, inserting equations (15) and (14) into equation (11), the detailed expression for the isotropic yield function becomes

$$
\begin{aligned}
f_{\text {iso }}= & p^{\prime}-p_{\mathrm{c} 0}^{\prime} \exp \left[\left(1+\gamma_{\beta} \log \frac{\pi}{\pi_{0}}\right) \beta_{0} \varepsilon_{\mathrm{v}}^{\mathrm{p}}\right] \\
& \times\left(1-\gamma_{\pi} \log \frac{\pi}{\pi_{0}}\right) r_{\text {iso }} \\
= & 0
\end{aligned}
$$

where the material parameters $\beta_{0}$ and $c_{r}$ (within the expression for $r_{\text {iso }}$ ) express the evolution of mechanical hardening, and $\gamma_{\pi}$ and $\gamma_{\beta}$ express the evolution of chemical hardening.

The isotropic behaviour is modelled with an associated flow rule as

$$
\begin{aligned}
f_{\text {iso }}= & g_{\text {iso }} \\
\mathrm{d} \varepsilon_{i j}^{\mathrm{p} \text {,iso }} & =\lambda_{\text {iso }}^{\mathrm{p}} \frac{\partial g_{\text {iso }}}{\partial \sigma_{i j}^{\prime}} \\
& =\frac{\lambda_{\text {iso }}^{\mathrm{p}}}{3}
\end{aligned}
$$

Deviatoric chemo-plastic mechanism. The deviatoric chemoplastic mechanism is an extension of the original Cam-clay model, as presented by Roscoe \& Burland (1968) and Hujeux (1979). It is defined in the $q-p^{\prime}$ plane as

$$
f_{\mathrm{dev}}=q-M p^{\prime}\left(1-b \ln \frac{p}{p_{\mathrm{c}}^{\prime}}\right) r_{\mathrm{dev}}
$$

where $M$ is the critical state parameter, $b$ is a material parameter defining the shape of the deviatoric yield limit, $d$ is the ratio between the yield and critical state mean effec- 
tive stresses, and $r_{\mathrm{dev}}$ is the degree of mobilisation of the deviatoric yield limit.

The critical state parameter $M$ depends on the shear strength angle at the critical state, $\phi^{\prime}$, according to

$$
M=\frac{6 \sin \phi^{\prime}}{3-\sin \phi^{\prime}}
$$

The progressive evolution of $r_{\mathrm{dev}}$ is defined by (Hujeux, 1979)

$$
\begin{aligned}
& r_{\mathrm{dev}}=r_{\mathrm{dev}}^{\mathrm{e}}+\frac{\varepsilon_{\mathrm{d}}^{\mathrm{p}}}{a+\varepsilon_{\mathrm{d}}^{\mathrm{p}}} \\
& \mathrm{d} r_{\mathrm{dev}}=\frac{\left(1-r_{\mathrm{dev}}\right)^{2}}{a} \mathrm{~d} \varepsilon_{\mathrm{d}}^{\mathrm{p}}
\end{aligned}
$$

where $r_{\mathrm{dev}}^{\mathrm{e}}$ and $a$ are material parameters defining the size of the elastic nuclei, and $\varepsilon_{\mathrm{d}}^{\mathrm{p}}$ is the deviatoric plastic strain.

Therefore, inserting equations (14) and (15) into equation (19), the expression for the deviatoric yield function becomes

$$
\begin{aligned}
f_{\mathrm{dev}}= & q \\
& -M p^{\prime}\left[\begin{array}{c}
1-b \ln \frac{p^{\prime} d}{p_{\mathrm{c} 0}^{\prime} \exp \left\{\left[1+\gamma_{\beta} \log \left(\pi / \pi_{0}\right)\right] \beta_{0} \varepsilon_{\mathrm{v}}^{\mathrm{p}}\right\}} \\
\times\left[1-\gamma_{\pi} \log \left(\pi / \pi_{0}\right)\right]
\end{array}\right] r_{\mathrm{dev}} \\
= & 0
\end{aligned}
$$

The hardening and dilatancy rules are as follows.

$$
\begin{aligned}
\mathrm{d} \varepsilon_{i j}^{\mathrm{p}, \mathrm{dev}} & =\lambda_{\mathrm{dev}}^{\mathrm{p}} \frac{\partial g_{\mathrm{dev}}}{\partial \sigma_{i j}^{\prime}} \\
& =\lambda_{\mathrm{dev}}^{\mathrm{p}} \frac{1}{M p^{\prime}}\left[\frac{\partial q}{\partial \sigma_{i j}^{\prime}}+\alpha\left(M-\frac{q}{p^{\prime}}\right) \frac{\delta_{i j}}{3}\right]
\end{aligned}
$$

with

$$
\begin{aligned}
& \frac{\partial q}{\partial \sigma_{i j}^{\prime}}= \begin{cases}\frac{3}{2 q}\left(\sigma_{i j}^{\prime}-p^{\prime}\right) & \text { for } i=j \\
\frac{3 \sigma_{i j}^{\prime}}{2 q} & \text { for } i \neq j\end{cases} \\
& \mathrm{d} \varepsilon_{\mathrm{v}}^{\mathrm{p}, \operatorname{dev}}=\lambda_{\operatorname{dev}}^{\mathrm{p}} \frac{\partial g_{\mathrm{dev}}}{\partial p^{\prime}} \\
& =\lambda_{\mathrm{dev}}^{\mathrm{p}} \frac{\alpha}{M p^{\prime}}\left(M-\frac{q}{p^{\prime}}\right) \\
& \mathrm{d} \varepsilon_{\mathrm{d}}^{\mathrm{p}}=\lambda_{\mathrm{dev}}^{\mathrm{p}} \frac{\partial g_{\mathrm{dev}}}{\partial q} \\
& =\lambda_{\mathrm{dev}}^{\mathrm{p}} \frac{1}{M p^{\prime}}
\end{aligned}
$$

where $\alpha$ is a material parameter introducing the non-associative behaviour.

Coupling. The two mechanisms are linked through the hardening variable $\varepsilon_{\mathrm{v}}^{\mathrm{p}}$. Therefore, a fully coupled behaviour can be represented. The yield stress limit depends on this parameter, and it appears in both expressions for the yield functions. This causes the isotropic yield surface to stretch when the deviatoric yield surface is expanded, and vice versa, as shown in Fig. 11.

When the two mechanisms are activated simultaneously,

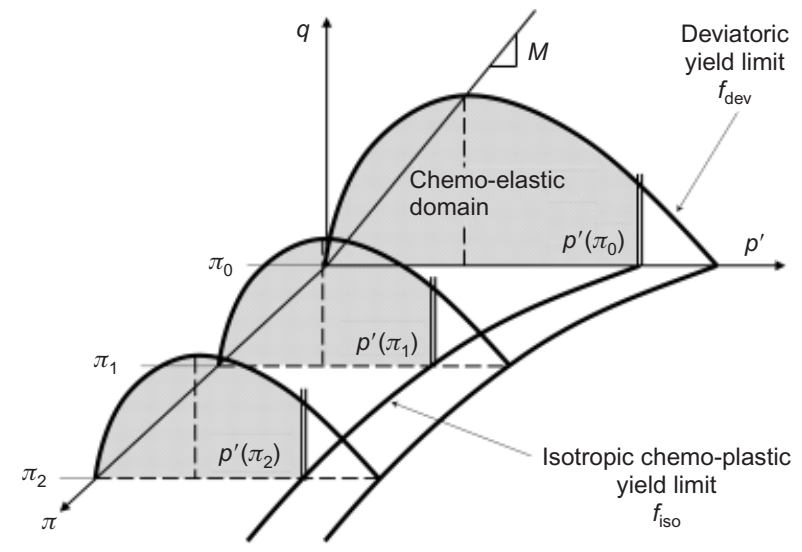

Fig. 11. Coupling of isotropic and deviatoric mechanisms of chemo-mechanical constitutive model ACMEG-C

the volumetric plastic strain is the sum of the components corresponding to both processes, according to

$$
\begin{aligned}
\mathrm{d} \varepsilon_{\mathrm{v}}^{\mathrm{p}} & =\lambda_{\mathrm{dev}}^{\mathrm{p}} \frac{\partial g_{\mathrm{dev}}}{\partial p^{\prime}}+\lambda_{\text {iso }}^{\mathrm{p}} \frac{\partial g_{\text {iso }}}{\partial p^{\prime}} \\
& =\lambda_{\mathrm{dev}}^{\mathrm{p}} \frac{\alpha}{M p^{\prime}}\left(M-\frac{q}{p^{\prime}}\right)+\lambda_{\text {iso }}^{\mathrm{p}}
\end{aligned}
$$

The two consistency equations must be met simultaneously, resulting in the need to solve the following set of two equations with two unknowns.

$$
\begin{aligned}
& \mathrm{d} \boldsymbol{F}=\frac{\partial \boldsymbol{F}}{\partial \boldsymbol{\sigma}^{\prime}}: \mathrm{d} \boldsymbol{\sigma}^{\prime}+\frac{\partial \boldsymbol{F}}{\partial \pi} \mathrm{d} \pi+\frac{\partial \boldsymbol{F}}{\partial \boldsymbol{\omega}} \cdot \frac{\partial \boldsymbol{\omega}}{\partial \lambda^{\mathrm{p}}} \cdot \lambda^{\mathrm{p}} \\
& =\boldsymbol{s}: \mathrm{d} \boldsymbol{\sigma}^{\prime}+\boldsymbol{\Pi} \mathrm{d} \pi-\mathbf{H} \cdot \lambda^{\mathrm{p}} \\
& \leqslant 0 \\
& \lambda^{\mathrm{p}} \geqslant 0 \\
& \mathrm{~d} \boldsymbol{F} \cdot \boldsymbol{\lambda}^{\mathrm{p}} \geqslant 0
\end{aligned}
$$

where $\boldsymbol{\sigma}^{\prime}$ is the stress tensor, $\boldsymbol{\omega}$ is the internal variable vector, $\boldsymbol{s}$ collects the stress gradients and $\boldsymbol{\Pi}$ is the derivative of the loading functions $\boldsymbol{F}$ with respect to the osmotic suction. $\mathbf{H}$ is the matrix of the hardening moduli, with $H_{\alpha \beta}=-\partial f_{\alpha} / \partial \lambda_{\beta}^{\mathrm{p}}, \lambda^{\mathrm{p}}$ is the plastic multiplier vector, and $\mathrm{d} \boldsymbol{F} \leqslant \mathbf{0}$ expresses Prager's consistency condition extended for multi-dissipative processes.

\section{NUMERICAL MODELLING}

Calibration

Mechanical behaviour. The results of one of the mechanical oedometric tests on a sample prepared with distilled water allowed the reference elastic bulk modulus, the reference shear modulus and the plastic potential parameter to be determined as

$$
\begin{aligned}
& K_{\text {ref }, 0}=2.303 \frac{1+e_{0}}{C_{\mathrm{s} 0}} p_{\text {ref }}^{\prime} \\
& G_{\text {ref }}=\frac{3 K_{\text {ref }, 0}\left(1-K_{0}\right)}{2+4 K_{0}}
\end{aligned}
$$

Assuming that $K_{0}=1-\sin \phi^{\prime}$

$$
\beta_{0}=2 \cdot 303 \frac{1+e_{0}}{C_{\mathrm{c}}-C_{\mathrm{s} 0}}
$$

where $p_{\text {ref }}^{\prime}=1 \mathrm{MPa}$ is the reference mean effective stress, $e_{0}$ is the initial void ratio, $C_{\mathrm{c}}$ is the compression index, $C_{\mathrm{s} 0}$ is 
the slope of the oedometric curve upon first loading, and $K_{0}$ is the lateral stress ratio for one-dimensional strain. The shear strength angle of the tested illite is $\phi^{\prime}=25^{\circ}$ (obtained from complementary triaxial tests). The other parameters of the mechanical part of the model were determined by fitting the curve of the test results. These parameters can be found in Table 3. The results of the simulation are presented in Fig. 12.

Chemo-mechanical behaviour. The parameters defining the chemo-mechanical behaviour of the model are determined through curve-fitting processes on the results of the

Table 3. Model parameters for simulation of mechanical response of illite mixed with distilled water and for simulation of chemomechanical response of illite-sodium chloride solution mixtures

Elastic parameters

\begin{tabular}{l|c}
\hline$K_{\text {ref }, 0}: \mathrm{MPa}$ & 560 \\
$G_{\text {ref }}: \mathrm{MPa}$ & 165 \\
$n^{\mathrm{e}}$ & 1 \\
\hline
\end{tabular}

Isotropic plastic parameters

\begin{tabular}{l|c}
\hline$\beta_{0}$ & $37 \cdot 7$ \\
$c$ & $0 \cdot 002$ \\
$r_{\text {iso }}^{\mathrm{e}}$ & $0 \cdot 2$ \\
\hline
\end{tabular}

Deviatoric plastic parameters

\begin{tabular}{l|c}
\hline$b$ & $0 \cdot 6$ \\
$d$ & 1 \\
$\phi^{\prime}:$ degrees & 25 \\
$\alpha$ & 1 \\
$a$ & $0 \cdot 02$ \\
$r_{\text {dev }}^{\mathrm{e}}$ & $0 \cdot 5$ \\
\hline
\end{tabular}

Chemo-mechanical parameters

\begin{tabular}{l|l}
\hline$\delta$ & 0.229 \\
$\gamma_{\pi}$ & 0.242 \\
$\gamma_{\beta}$ & 0.056 \\
\hline
\end{tabular}

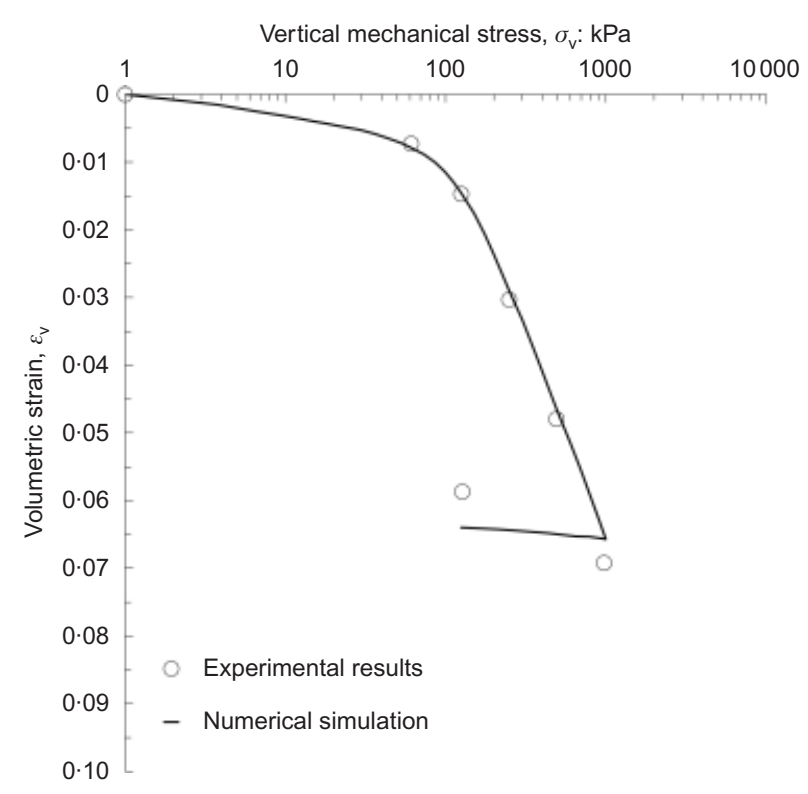

Fig. 12. Simulation of one oedometric test under mechanical loading only using chemo-mechanical constitutive model ACMEG-C oedometric tests under mechanical loading. The chemical form factors $\delta, \gamma_{\pi}$ and $\gamma_{\beta}$ are determined using plots of the oedometric modulus, yield stress and plastic stiffness modulus respectively against the osmotic suction. The values of the three parameters are presented in Table 3. These parameters were used to simulate three of the other oedometric tests under mechanical loading. The results of the simulation are plotted in Fig. 13. The model results correspond well with the experimental results.

\section{Verification}

The calibration of the numerical model has been verified with two tests under both mechanical and chemical loading. These tests were conducted at a higher initial void ratio, $e_{0}=1 \cdot 03$. To take this difference into account, $p_{\mathrm{c} 0}^{\prime}$, the representative initial yield stress at a reference osmotic suction $\pi_{0}$, and its evolution were calculated through the results of the oedometer tests at $\pi=0.61 \mathrm{MPa}$ and the vertical yield stress-osmotic suction plot (Fig. 5). The simulations were then run for stress paths $\mathrm{C} 1$ and $\mathrm{C} 2$, including a chemical loading step at approximately $30 \mathrm{kPa}$ and $80 \mathrm{kPa}$ in the first and second cases respectively. Their stress paths are presented in Figs 14 and 16 respectively, and the simulations are presented in Figs 15 and 17 respectively. The model and experimental results correspond well, at least until the chemical loading. The discrepancies between the experimental and the modelling results can be addressed separately for the two stress paths. For test $\mathrm{C} 1$, the reduction in volume associated with the chemical loading is well reproduced. The analysis of the stress path in Fig. 14 and the experimental points in Fig. 15 would suggest that the vertical yield stress moved further than the value of vertical stress at which the chemical loading occurred. In this sense, during the subsequent increment of the vertical load, a more pronounced transition from an elastic to an elasto-plastic response should have been observed. For a better prediction of this trend with the numerical simulation, a refinement of the selection of the $r_{\text {iso }}$ value (equations (12) and (13)) could be considered. For stress path $\mathrm{C} 2$, the vertical deformation associated with the chemical loading is slightly overestimated. It is worth mentioning that this deformation is modelled solely through the dependence functions of the oedometric modulus, yield stress and plastic stiffness

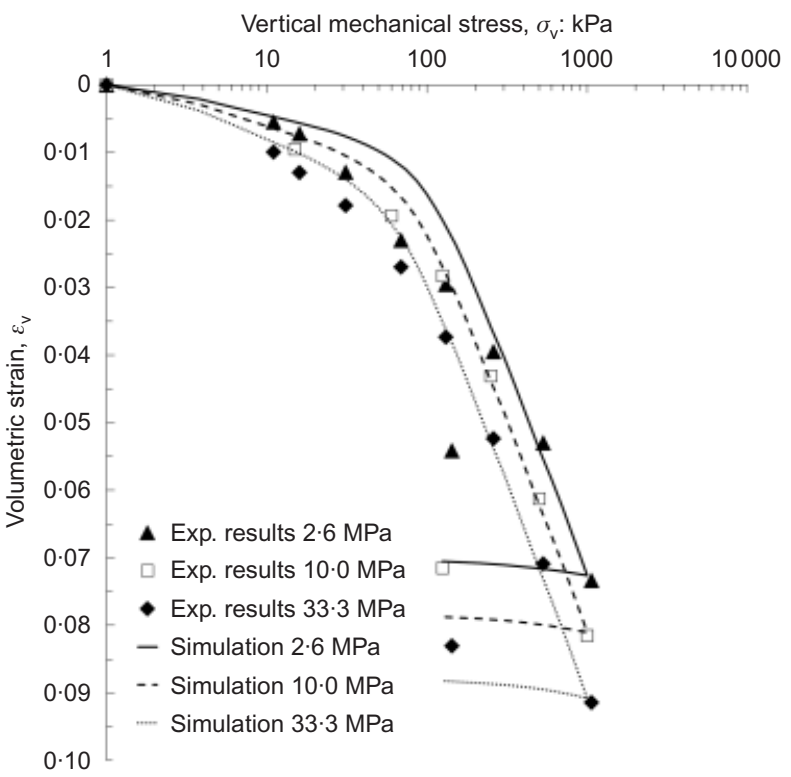

Fig. 13. Simulation of three of the oedometric tests under mechanical loading only using constitutive model ACMEG-C 


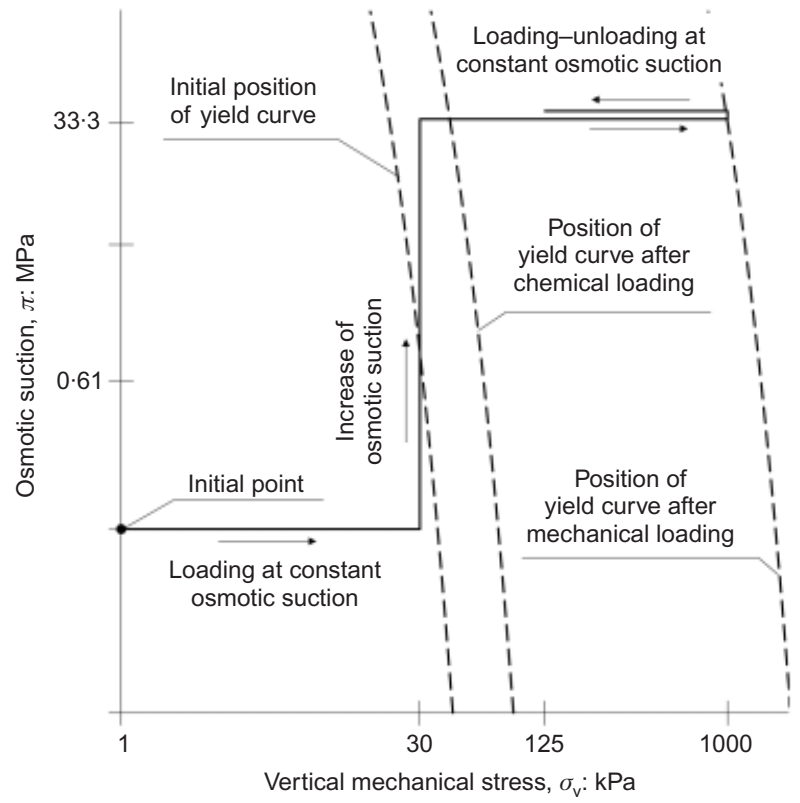

Fig. 14. Stress paths of oedometric test including chemical loading step at vertical stress of approximately $30 \mathrm{kPa}$, including evolution of yield curve

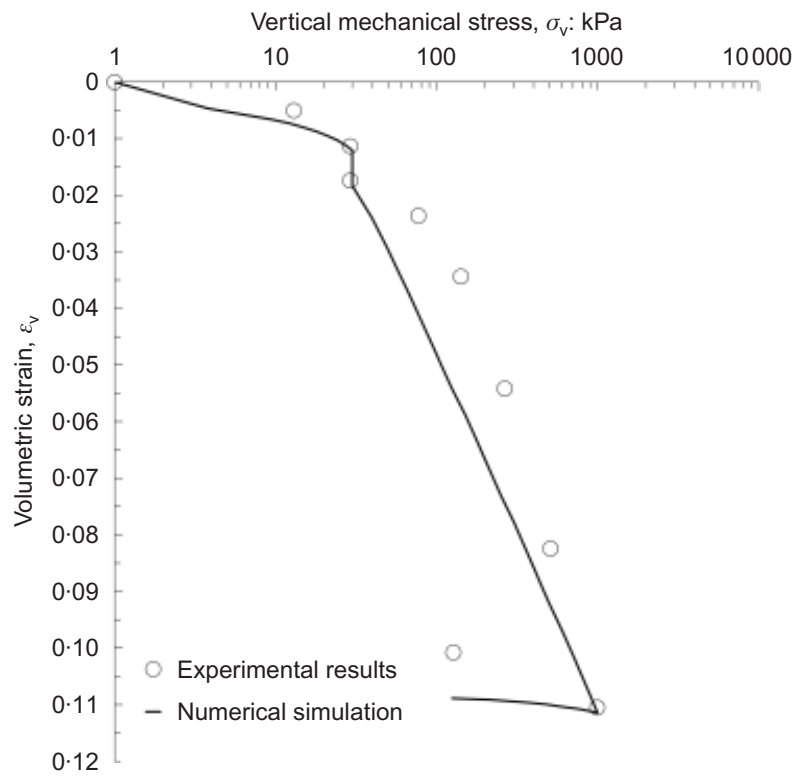

Fig. 15. Simulation of oedometric tests under mechanical loading and chemical loading step at vertical mechanical stress of approximately $30 \mathrm{kPa}$ using chemo-mechanical constitutive model ACMEG-C

modulus. The slope of the plastic deformation and its order of magnitude are well predicted.

\section{CONCLUSIONS}

Despite the vast number of situations in which couplings between chemistry and mechanics occur, the available constitutive models rely on limited experimental evidence. This study extends the experimental database on the subject of one-dimensional consolidation induced by a change in the chemical composition in the pore liquid. In contrast to earlier contributions, the osmotic suction, controlled through the sodium chloride concentration in the pore water, is considered to be the governing variable.

A laboratory programme was conducted. The total, matric

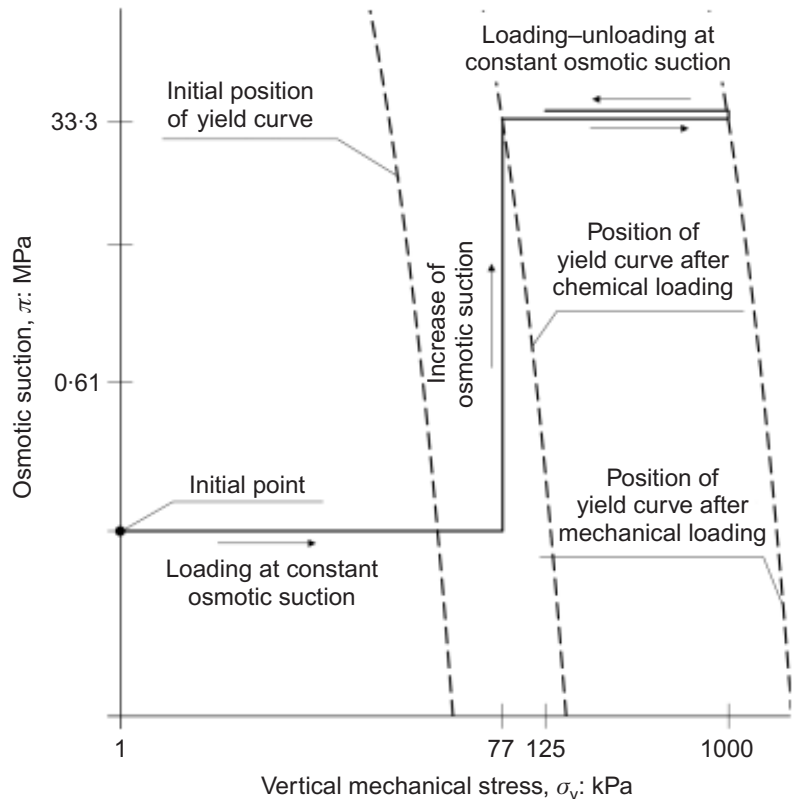

Fig. 16. Stress paths of oedometric test with chemical loading step at vertical stress of approximately $80 \mathrm{kPa}$, including evolution of yield curve

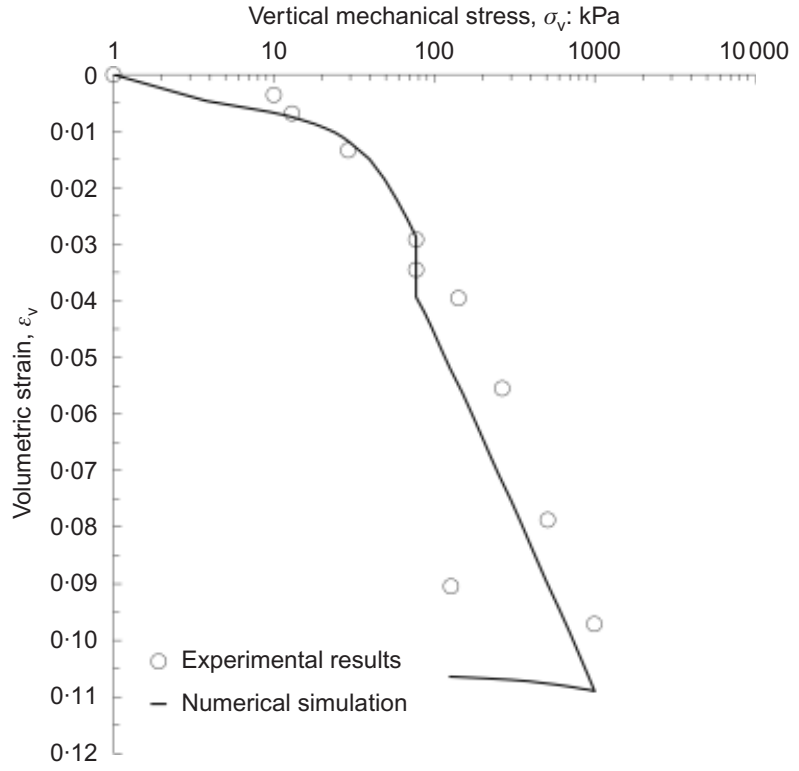

Fig. 17. Simulation of oedometric tests under mechanical loading and chemical loading step at vertical mechanical stress of approximately $80 \mathrm{kPa}$ using chemo-mechanical constitutive model ACMEG-C

and osmotic suctions of the clay mixtures of illite powder and distilled water or sodium chloride solutions were determined. Mixtures of the same composition were then subjected to conventional oedometric tests. Furthermore, two clay mixtures prepared with distilled water were subjected to a conventional oedometric test including a chemical loading path performed with incremental increases in the osmotic suction.

From the suction determination, an empirical relationship was determined for the osmotic suction as a function of the sodium chloride concentration of the pore liquid. This relationship followed a polynomial of the second order. Subsequently, oedometric test results showed that the oedometric modulus upon first loading and the vertical yield stress decreased as the osmotic suction increased, whereas 
the compression and swelling indices were independent of the suction. Finally, the rate of consolidation due to chemical solicitation was shown to follow a straight line in the $\varepsilon_{\mathrm{v}}-$ $\log \pi$ diagram, and its slope did not change significantly within the applied void ratio and vertical mechanical stress ranges.

The findings allowed an extension of the ACMEG constitutive framework to be developed. ACMEG-C (chemical effect) is able to take changes in osmotic suction into account, as well as the evolution of elastic and plastic material parameters and the plastic deformation induced by these changes. The mechanical behaviour was calibrated with one oedometric test on a sample prepared with distilled water, whereas the chemo-mechanical behaviour was calibrated with the oedometric test results under mechanical loading. In all cases, the model results corresponded well with the test results. The model was validated through the two tests, including a chemical loading path. These stress paths show that a large part of the chemo-mechanical oedometric test can be predicted well. Improvements could be made by taking into account the evolution of the oedometric modulus and the compression indices, as well as by researching the elastic behaviour after changing the direction of the loading.

Further study should also include the investigation of different kinds of salt and clay powder, to verify the proposed independence of the materials. Only then can previous results used, such as those by Di Maio and coworkers (Di Maio, 1996; Di Maio \& Fenelli, 1997; Di Maio \& Onorati, 1999), be properly compared.

\section{ACKNOWLEDGEMENTS}

The authors would like to thank the Mont Terri Project and NAGRA for their support.

\author{
NOTATION \\ a material parameter defining size of elastic nuclei \\ $b$ material parameter defining shape of deviatoric yield limit \\ $C_{\mathrm{c}}$ compression index \\ $C_{\mathrm{s}} \quad$ swelling index \\ $C_{\mathrm{s} 0}$ slope of oedometric curve upon first loading \\ $c$ sodium chloride concentration \\ $c_{r}$ material parameter \\ $d$ ratio between yield and critical-state mean effective \\ stresses \\ $E_{\text {oed }}$ oedometric modulus \\ $e_{0}$ initial void ratio \\ $\boldsymbol{F}$ vector containing the loading functions \\ $f_{\text {dev }}$ yield function for deviatoric mechanism \\ $f_{\text {iso }}$ yield function for isotropic mechanism \\ $G$ hypoelastic shear modulus \\ $G_{\text {ref }}$ reference shear modulus \\ $g_{\mathrm{k}}$ plastic potential \\ $\mathbf{H}$ matrix of hardening moduli \\ $K$ hypoelastic bulk modulus \\ $K_{\text {ref }}$ reference bulk modulus \\ $K_{\text {ref,0 }}$ reference bulk modulus at reference osmotic suction \\ $K_{0}$ lateral stress ratio for one-dimensional strain \\ $M$ critical state parameter \\ $n_{\mathrm{e}}$ material parameter \\ $p^{\prime}$ mean effective stress \\ $p_{\mathrm{c}}^{\prime}$ mean yield stress \\ $p_{\mathrm{c} 0}^{\prime}$ mean effective yield stress at reference osmotic suction \\ $p_{\text {ref }}^{\prime}$ reference mean effective stress \\ $q$ deviatoric stress \\ $R$ universal gas constant \\ $r_{\mathrm{dev}}$ degree of mobilisation of deviatoric yield limit \\ $r_{\mathrm{dev}}^{\mathrm{e}}$ material parameter defining size of elastic nuclei \\ $r_{\text {iso }}$ degree of mobilisation of isotropic yield limit \\ $r_{\text {iso }}^{\mathrm{e}} \quad$ material parameter defining size of elastic nuclei
}

s stress gradient vector

$s_{\mathrm{m}}$ matric suction

$T$ absolute temperature

$w_{0}$ initial water content

$\alpha$ material parameter introducing non-associative behaviour

$\beta$ plastic stiffness modulus

$\beta_{0}$ plastic stiffness modulus at reference osmotic suction

$\gamma_{\beta}$ chemical evolution factor

$\gamma_{\pi}$ chemical evolution factor for yield stress

$\delta$ material parameter

$\boldsymbol{\varepsilon}$ strain tensor

$\mathrm{d} \varepsilon_{i j}$ total strain increment

$\varepsilon_{i j}^{\mathrm{e}} \quad$ chemo-elastic strain tensor

$\varepsilon_{i j}^{\mathrm{p}} \quad$ chemo-plastic strain tensor

$\mathrm{d} \varepsilon_{i j}^{\mathrm{p}, k} \quad$ 'partial' plastic strain increment for mechanism $\mathrm{k}$

$\varepsilon_{\mathrm{d}}^{\mathrm{e}} \quad$ chemo-elastic deviatoric strain

$\varepsilon_{\mathrm{d}}^{\mathrm{p}} \quad$ deviatoric plastic strain

$\varepsilon_{\mathrm{V}} \quad$ volumetric strain

$\varepsilon_{\mathrm{v}}^{\mathrm{e}} \quad$ chemo-elastic volumetric strain

$\varepsilon_{\mathrm{v}}^{\mathrm{p}}$ plastic volumetric strain

$\varepsilon_{\mathrm{v}}^{\mathrm{p} \text {,iso }}$ volumetric plastic strain induced by isotropic mechanism

$\lambda_{k}^{\mathrm{p}} \quad$ plastic multiplier for mechanism $k$

$\lambda^{\mathrm{p}}$ plastic multiplier vector

$v$ number of constituent ions

$\pi$ osmotic suction

$\pi_{0}$ initial osmotic suction

$\rho_{\text {solution }}$ density of solution

$\boldsymbol{\sigma}^{\prime}$ effective stress tensor

$\sigma_{i j}^{\prime} \quad$ effective stress tensor

$\sigma_{\mathrm{c}} \quad$ vertical yield stress

$\sigma_{\mathrm{c} 0} \quad$ vertical yield stress at $\pi_{0}$

$\sigma_{\mathrm{v}} \quad$ vertical stress

$\phi^{\prime} \quad$ shear strength angle at critical state

$\psi$ total suction

$\omega$ internal variable vector

\section{REFERENCES}

Barbour, S. L. \& Fredlund, D. G. (1989). Mechanisms of osmotic flow and volume change in clay soils. Can. Geotech. J. 26, No. 4, 551-562.

Biot, M. A. (1941). General theory of three-dimensional consolidation. J. Appl. Phys. 12, No. 2, 155-164.

Biot, M. A. (1956a). Thermoelasticity and irreversible thermodynamics. J. Appl. Phys. 27, No. 3, 240-253.

Biot, M. A. (1956b). Theory of deformation of a porous viscoelastic anisotropic solid. J. Appl. Phys. 27, No. 5, 459-467.

Biot, M. A. (1973). Nonlinear and semilinear rheology of porous solids. J. Geophys. Res. 78, No. 23, 4924-4937.

Bolt, G. H. (1956). Physico-chemical analysis of the compressibility of pure clays. Géotechnique 6, No. 2, 86-93, http://dx.doi.org/ 10.1680/geot.1956.6.2.86.

Bolt, G. H. \& Miller, R. D. (1955). Compression studies of illite suspensions. Soc. Soil Sci. Am. J. 19, No. 3, 285-288.

Boukpeti, N., Charlier, R. \& Hueckel, T. (2004). Modelling contamination of clays. In Coupled thermo-hydro-mechanical-chemical processes in geo-systems: Fundamentals, modelling, experiments and applications (ed. O. Stephansson), Vol. 2, pp. 523-528. Amsterdam, the Netherlands: Elsevier.

Bunger, A. P. (2010). The Mandel-Cryer effect in chemoporoelasticity. Int. J. Numer. Anal. Methods Geomech. 34, No. 14, 14791511.

Cardoso, R., Romero, E., Lima, A. \& Ferrari, A. (2007). A comparative study of soil suction measurement using two different high-range psychrometers. Proc. 2nd Int. Conf. on Mechanics of Unsaturated Soils, Weimar, pp. 79-93.

Chapman, D. L. (1913). A contribution to the theory of electrocapillarity. Phil. Mag. Ser. 6, 25, No. 148, 475-481.

Coussy, O. (2004). Poromechanics. Hoboken, NJ, USA: John Wiley \& Sons.

Dafalias, Y. \& Herrmann, L. (1980). A bounding surface soil plasticity model. Proceedings of the international symposium on soils under cyclic and transient loading, Swansea, pp. 335-345.

Di Maio, C. (1996). Exposure of bentonite to salt solution: osmotic 
and mechanical effects. Géotechnique 46, No. 4, 695-707, http://dx.doi.org/10.1680/geot.1996.46.4.695.

Di Maio, C. \& Fenelli, G. B. (1997). Influenza delle interazioni chimico-fisiche sulla deformabilità di alcuni terreni argillosi. Riv. Ital. Geotec., No. 1, 695-707.

Di Maio, C. \& Onorati, R. (1999). Prove di laboratorio: Influenza della composizione del liquido di cella. Rendiconti del XX Convegno Nazionale di Geotecnica, Parma, 87-94.

Fernandez, F. \& Quigley, R. M. (1985). Hydraulic conductivity of natural clays permeated with simple liquid hydrocarbons. Can. Geotech. J. 22, No. 2, 205-214.

Fernandez, F. \& Quigley, R. M. (1991). Controlling the destructive effect of clay-organic liquid interactions by application of effective stresses. Can. Geotech. J. 28, No. 3, 388-398.

François, B. \& Laloui, L. (2008). ACMEG-TS: a constitutive model for unsaturated soils under non-isothermal conditions. Int. J. Numer. Anal. Methods Geomech. 32, No. 16, 1955-1988.

Fritz, S. J. (1986). Ideality of clay membranes in osmotic processes: a review. Clays Clay Miner. 34, No. 2, 214-223.

Gajo, A. \& Loret, B. (2003). Finite element simulations of chemomechanical coupling in elastic-plastic homoionic expansive clays. Comput. Methods Appl. Mech. Engng 192, No. 31-32, 3489-3530.

Gajo, A., Loret, B. \& Hueckel, T. (2002). Electro-chemo-mechanical couplings in saturated porous media: elastic-plastic behaviour of heteroionic expansive clays. Int. J. Solids Struct. 39, No. $16,4327-4362$.

Gens, A. (2010). Soil-environment interactions in geotechnical engineering. Géotechnique 60, No. 1, 3-74, http://dx.doi.org/ 10.1680/geot.9.P.109.

Guimarães, L. Do N., Gens, A. \& Olivella, S. (2007). Coupled thermo-hydro-mechanical and chemical analysis of expansive clay subjected to heating and hydration. Transp. Porous Media 66, No. 3, 341-372.

Gouy, G. (1910). Constitution of the electric charge at the surface of an electrolyte. J. Physique 9, No. 4, 457-467.

Heidug, W. \& Wong, S. W. (1996). Hydration swelling of waterabsorbing rocks: a constitutive model. Int. J. Numer. Anal. Methods Geomech. 20, No. 6, 403-430.

Hueckel, T. (1997). Chemo-plasticity of clays subjected to stress and flow of a single contaminant. Int. J. Numer. Anal. Methods Geomech. 21, No. 1, 43-72.

Hujeux, J. C. (1979). Calcul numérique de problèmes de consolidation élastoplastique. $\mathrm{PhD}$ thesis, Ecole Centrale de Paris, Paris, France.

Kaczmarek, M. \& Hueckel, T. (1998). Chemo-mechanical consolidation of clays: analytical solutions for a linearized one-dimensional problem. Transp. Porous Media 32, No. 1, 49-74.

Koiter, W. T. (1960). General theorems for elastic-plastic solids. In Progress in solid mechanics (eds I. N. Sneddon and R. Hill), pp. 167-221. Amsterdam, the Netherlands: North-Holland.

Koliji, A., Laloui, L. \& Vulliet, L. (2010). Constitutive modeling of unsaturated aggregated soils. Int. J. Numer. Anal. Methods Geomech. 34, No. 17, 1846-1876.

Laloui, L. \& François, B. (2009). ACMEG-T: soil thermoplasticity model. J. Engng Mech. 135, No. 9, 932-944.

Laloui, L. \& Nuth, M. (2009). On the use of the generalised effective stress in the constitutive modelling of unsaturated soils. Comput. Geotech. 36, No. 1-2, 20-23.

Laloui, L., Nuth, M. \& François, B. (2010). Mechanics of unsaturated soils In Mechanics of unsaturated geomaterials (ed. L. Laloui), pp. 29-51. Hoboken, NJ, USA: John Wiley \& Sons.

Leong, E.-C., Tripathy, S. \& Rahardjo, H. (2003). Total suction measurement of unsaturated soils with a device using the chilled-mirror dew point technique. Géotechnique 53, No. 2, 173-182, http://dx.doi.org/10.1680/geot.2003.53.2.173.

Loret, B., Hueckel, T. \& Gajo, A. (2002). Chemo-mechanical coupling in saturated porous media: elastic-plastic behaviour of homoionic expansive clays. Int. J. Solids Struct. 39, No. 10, 2773-2806.

Mandel, W. (1965). Généralisation de la théorie de Koiter. Int. J. Solids Struct. 1, No. 3, 273-295.

Marine, I. W. \& Fritz, S. J. (1981). Osmotic model to explain anomalous hydraulic heads. Water Resour. Res. 17, No. 1, $73-82$.

Mesri, G. \& Olson, R. E. (1970). Shear strength of montmorillonite. Géotechnique 20, No. 3, 261-270, http://dx.doi.org/10.1680/ geot.1970.20.3.261.

Mesri, G. \& Olson, R. E. (1971). Consolidation characteristics of montmorillonite. Géotechnique 21, No. 4, 341-352, http:// dx.doi.org/10.1680/geot.1971.21.4.341.

Mitchell, J. K. \& Soga, K. (2005). Fundamentals of soil behavior. Hoboken, NJ, USA: John Wiley \& Sons.

Mitchell, J. K., Greenberg, J. A. \& Witherspoon, P. A. (1973). Chemico-osmotic effects in fine-grained soils. In Selected Papers of James K. Mitchell (eds J. K. Mitchell and I. M. Idriss), pp. 398-413. Reston, VA, USA: ASCE.

Rizzi, E., Maier, G., \& Willam, K. (1996). On failure indicators in multi-dissipative materials. Int. J. Solids Struct. 33, No. 20-22, $3187-3214$.

Roscoe, K. H. \& Burland, J. B. (1968). On the generalized stressstrain behaviour of 'wet' clay. In Engineering plasticity (eds J. Heyman and F. A. Leckie), pp. 535-609. Cambridge, UK: Cambridge University Press

Sarout, J. \& Detournay, E. (2011). Chemoporoelastic analysis and experimental validation of the pore pressure transmission test for reactive shales. Int. J. Rock Mech. Mining Sci. 48, No. 5, $759-772$

Sherwood, J. D. (1993). Biot poroelasticity of a chemically active shale. Proc. R. Soc. London Ser. A 440, No. 1909, 365-377.

Sherwood, J. D. (1994). A model of hindered solute transport in a poroelastic shale. Proc. R. Soc. London Ser. A 445, No. 1925, 679-692.

Sridharan, A. \& Venkatappa Rao, G. (1973). Mechanisms controlling volume change of saturated clays and the role of the effective stress concept. Géotechnique 23, No. 3, 359-382, http://dx.doi.org/10.1680/geot.1973.23.3.359.

Sridharan, A. \& Venkatappa Rao, G. (1979). Shear strength behaviour of saturated clays and the role of the effective stress concept. Géotechnique 29, No. 2, 177-193, http://dx.doi.org/ 10.1680/geot.1979.29.2.177.

Verwey, E. J. W. \& Overbeek, J. Th. G. (1948). Theory of the stability of lyophobic colloids. New York, NY, USA: Elsevier. 